\title{
Morbidity and Mortality pattern of neonatal intensive care unit in a Medical College Hospital from South India
}

\author{
Chandrakala R Iyer ${ }^{1}$, Gornale $V_{K}^{2}$, Harsha $P^{3}$, Katwe $N^{4}, \operatorname{Prasad}^{5}$, Keerthivardhan $\mathbf{Y}^{6}$ \\ ${ }^{1}$ Dr. Chandrakala R. Iyer DCH, DNB, MRCPch, Assistant Professor, Department of Pediatrics, ${ }^{2}$ Dr. Vinod Kumar \\ Gornale, MBBS, MD. Assistant Professor, Department of Pediatrics, ${ }^{3}$ Dr. Harsha PJ, MBBS, DCH, MD, Assistant \\ Professor, Department of Pediatrics, ${ }^{4}$ Dr. Nagendra Katwe, MBBS, MD, Professor, Department of Pediatrics, ${ }^{5}$ Suhas \\ Prasad. V, MBBS. Postgraduate Student, ${ }^{6}$ Keerthivardhan Y, MBBS. Postgraduate Student, All are affiliated with P.E.S. \\ Medical College, Kuppam. A.P. India.
}

\begin{abstract}
Background: Neonatal outcome is a sensitive indicator of availability, utilization and effectiveness of obstetrics and neonatal health care in the community. Review of hospital based mortality and morbidity pattern is critical to improve the quality of health care delivery system in that hospital. Objectives: To study the morbidity and mortality pattern of neonates admitted to neonatal intensive care unit (NICU) of a rural medical college hospital. Material and methods: All the neonates admitted to NICU from July 2013 to June 2015 were retrospectively analysed for demographic profile, short term morbidity and outcome. Results: 1580 neonates were admitted in the study period. 59.5\% were Males, $63 \%$ were inborn, $75 \%$ were term babies and $59.5 \%$ had normal birth weight. $89.8 \%$ were admitted in early neonatal period. Important causes for admission were sepsis (24\%)), birth asphyxia (23.6\%), prematurity and low birth weight care (18.5\%), Respiratory problems (13.9\%) and hyperbilirubinemia (10.3\%). The outcome of the admitted babies showed 83\% discharges, $3.7 \%$ deaths, $12.2 \%$ discharge against medical advice and $1.96 \%$ referred to another centre. The major causes of mortality were birth asphyxia including hypoxic ischemic encephalopathy (45\%), sepsis (27.5\%) and respiratory problems $(27.5 \%)$. The survival of term as well as inborn babies was better than that of preterm and out born neonates respectively. Conclusion: Birth asphyxia, neonatal sepsis, prematurity and respiratory problems were major causes of both mortality and morbidity. There is need to strengthen services to address these problems more effectively.
\end{abstract}

Key words: Morbidity, Mortality, Newborn, Neonatal Intensive Care Unit.

\section{Introduction}

Newborn period is the most critical phase of life as they are prone to various diseases. Survival of the newborn is dependent on availability and accessibility to quality health care system. Though Progress has been made in the reduction of neonatal mortality rate (NMR) all over the world, it is not uniform. More than half $(53 \%)$ of all neonatal deaths is contributed by only five countries: India, Nigeria, Pakistan, China and Democratic Republic of the Congo [1]. According to the National Family Health Survey - 3 (NFHS-3) report, the current NMR in India, 39 per 1000 live births, accounts for nearly $77 \%$ of all the infant deaths $(57 / 1000)$ and nearly half of the under-five child deaths (74/1000)[2]. One of the Millennium Development Goals (MDG) is to reduce the number of childhood deaths under the age of five years by two thirds by the year 2015 [3].

Manuscript received: $20^{\text {th }}$ Oct 2015

Reviewed: $25^{\text {th }}$ Oct 2015

Author Corrected: $7^{\text {th }}$ Nov 2015

Accepted for Publication: $18^{\text {th }}$ Nov 2015
The MDG for child survival cannot be met without substantial reduction in neonatal mortality [4]. The NMR of India in rural areas is 33/1000 and that in urban areas is $16 / 1000$. The discrepancy is more marked in the states of Andhra Pradesh, Assam, Jharkhand, and Kerala where rural NMR is 2.5 times more than that of urban areas [5].

The major causes of newborn deaths in India are prematurity (35\%), neonatal infections (33\%), intra-partum related complications/ birth asphyxia (20\%) and congenital malformations (9\%)[5]. Neonatal deaths can be largely preventable. An analysis indicated that available interventions can reduce the three most common cause of neonatal mortality preterm, intrapartum, and infection-related deaths by $58 \%, 79 \%$, and $84 \%$, respectively [6]. 
As morbidity and mortality pattern is variable among different regions, we have opted to determine the institution specific data on neonatal morbidity and mortality pattern from our neonatal intensive care unit (NICU).

\section{Methodology}

A retrospective descriptive study was done on all the neonates admitted sequentially into NICU from July 2013 to June 2015 for a period of two years at PES medical college, Kuppam, Andhra Pradesh. Data of all neonates were collected from the admission, discharge, and death registers regarding place of birth, gestational age, sex, birth weight, diagnosis and outcome such as discharge, referrals, discharge against medical advice (DAMA) and deaths. This was entered in Microsoft excel and statistically analysed using two proportion test. $\mathrm{P}$ value $<0.05$ is taken as significant.

Setting: Our NICU has 10 incubators, 4 ventilators, 8 phototherapy units. There is availability of arterial blood gas, pulse oximeters, surfactant therapy and 24 hour laboratory as well as radiology services. The nurse to patient ratio of 1:1 for ventilated babies and 1:4 for other babies, a paediatrician exclusively posted to NICU in addition to a postgraduate resident and an intern.

\section{Results}

Table-1: Demographic profile of NICU admissions- 1580

\begin{tabular}{|c|c|c|c|c|}
\hline Parameters & Variables & Number & Percentage & Ratio \\
\hline \multirow[t]{2}{*}{ Place of Birth } & Inborn & 998 & 63.2 & \multirow{2}{*}{$1.7: 1$} \\
\hline & Out born & 582 & 36.8 & \\
\hline \multirow[t]{2}{*}{ Age at Admission } & $<7$ days & 1419 & 89.8 & \multirow{2}{*}{$9: 1$} \\
\hline & $>7$ days & 161 & 10.2 & \\
\hline \multirow[t]{2}{*}{ Sex } & Male & 941 & 59.6 & \multirow{2}{*}{$1.4: 1$} \\
\hline & Female & 639 & 40.4 & \\
\hline \multirow{2}{*}{$\begin{array}{l}\text { Gestational } \\
\text { Age }\end{array}$} & Preterm & 396 & 25 & \multirow{2}{*}{$1: 3$} \\
\hline & Term & 1184 & 75 & \\
\hline \multirow[t]{2}{*}{ Birth Weight } & $<2.5 \mathrm{~kg}^{*}$ & 641 & 40.6 & \multirow{2}{*}{$1: 1.4$} \\
\hline & $>2.5 \mathrm{~kg}$ & 939 & 59.4 & \\
\hline
\end{tabular}

$* 7.7 \%$ were Very low birth babies $<1.5 \mathrm{~kg}$.

A total of 1580 neonates admitted in NICU during the study period. Demographic profile (Table1) showed 998 (63\%) were inborn neonates. Male to female ratio was 1.4:1. A total of 1419 (89.8\%) neonates were admitted within 7 days of birth.

$75 \%$ of admitted neonates were term and $25 \%$ were preterm. $40.5 \%$ of admitted neonates had LBWs out of which $7.7 \%$ had very low birth weight. $351(22.2 \%)$ in born neonates with meconium stained amniotic fluid (MSAF) admitted to NICU for close observation in view of either mild respiratory distress requiring oxygen therapy or some needing
Preterm baby means live born neonate delivered before 37 weeks from 1st day of last menstrual period and weight $<2500 \mathrm{~g}$. Early neonatal period is age of the screen and positive blood culture examination when diagnosed in a baby with meconium-stained amniotic fluid having respiratory distress that persisted beyond 24 hours and requiring oxygen, with or without

Birth asphyxia was clinically diagnosed in babies with low Apgar score less than 7 needing resuscitation at birth. Out born babies with birth asphyxia had either ischemic encephalopathy (HIE) was staged according to Sarnat and Sarnat classification. Neonatal jaundice was diagnosed clinically and by assessing serum bilirubin. Hyaline membrane disease (HMD) was diagnosed in a preterm baby with respiratory distress having positive radiological features. the delivery. Low birth weight (LBW) means birth diagnosed mainly on clinical basis along with septic though they lacked documented Apgar score. Hypoxic 
immediate tracheal suction. Though they needed NICU admission initially for monitoring they were well babies and shifted to mother side within few hours. Hence they were not included as a cause of morbidity and excluded.

\section{Figure 1: Morbidity Pattern $(\mathbf{n = 1 2 4 1}) *$}

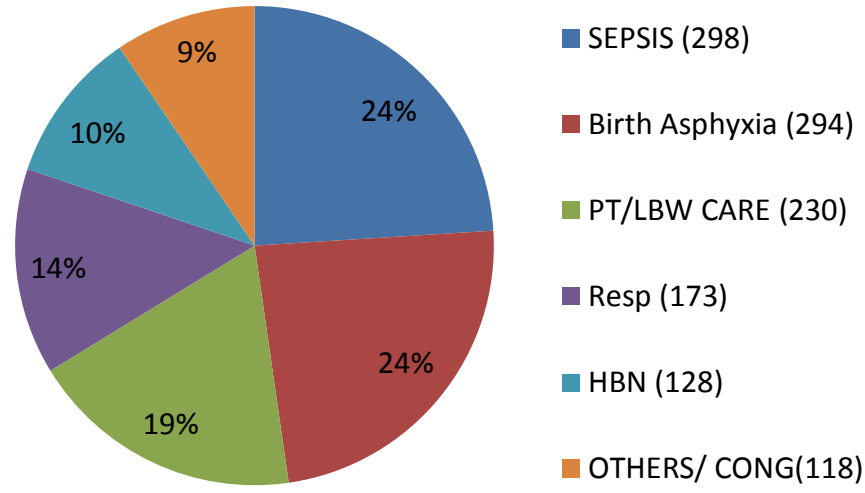

* 12 neonates had more than one morbidity and 351 neonates with MSAF excluded.

Common causes of morbidity in this study (Figure 1) were sepsis in $24 \%$ and birth asphyxia in 23.69 percent. $18.54 \%$ were primarily admitted for prematurity and/or LBW care though few later developed other problems. Other morbidities were respiratory problems in $13.94 \%$ including MAS, HMD, Bronchopneumonia (BP) and Transient tachypnea of newborn (TTN).

$10.31 \%$ neonates with hyperbilirubinemia needed photo therapy. 9.5\% had various reasons for admission, like congenital problems, feeding problems, excessive crying, vomiting, dehydration fever, sick mother and surgical causes.

\section{Figure 2: Outcome of admitted newborns}

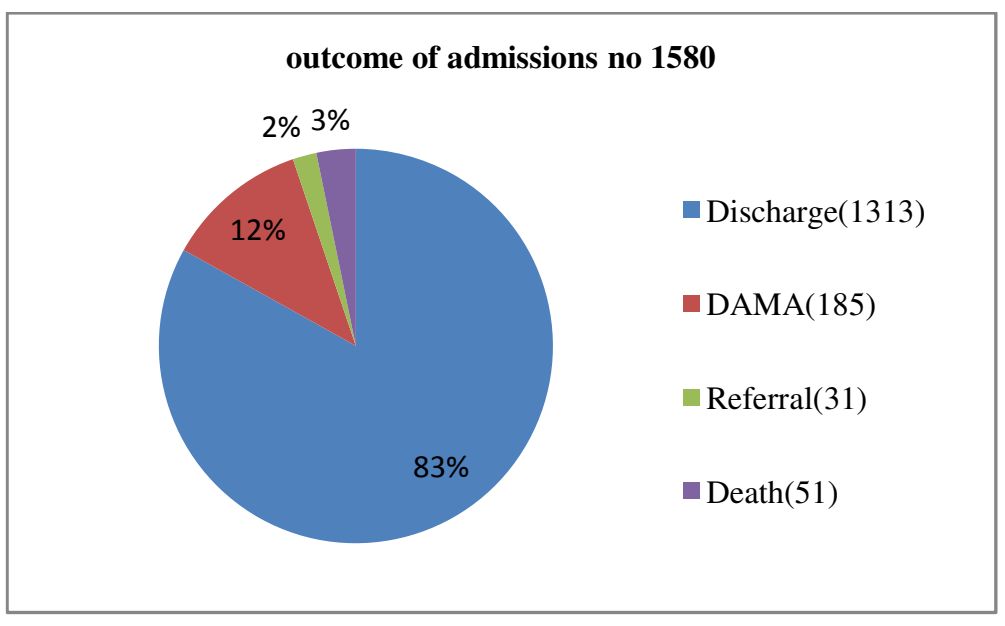

$83 \%$ of admitted neonates (Figure2) improved and were discharged from NICU. Discharge against medical advice (DAMA) constituted by 12.2 percent. $1.96 \%$ was referred to other hospitals due to surgical needs or as requested by the relatives.

Death rate of NICU was 3.2\%, but after excluding DAMA and referred neonates it was 3.7\%. 107 neonates needed ventilation. 
Table 2: Demographic profile of hospital mortality data (DAMA and referrals excluded)

\begin{tabular}{|l|c|c|c|c|c|}
\hline Parameters & Variables & $\begin{array}{c}\text { Number of } \\
\text { Deaths }\end{array}$ & $\begin{array}{c}\text { Number of } \\
\text { admissions }\end{array}$ & Percentage & P value \\
\hline Year & $2013-2014$ & 26 & 741 & 3.5 & \\
\cline { 2 - 5 } & $2014-2015$ & 25 & 623 & 4 & \\
\hline Place of Birth & \multirow{2}{*}{ IN-born } & 24 & 900 & 2.6 & 0.005 \\
\cline { 2 - 5 } & OUT-born & 27 & 464 & 5.8 & 0.006 \\
\hline Gestational Age & $\begin{array}{c}\text { Preterm } \\
\text { Term }\end{array}$ & 20 & 308 & 6.4 & 2.9 \\
\hline \multirow{2}{*}{ Birth weight } & Low birth weight & 31 & 1056 & 4.7 & 0.163 \\
\cline { 2 - 5 } & Normal weight & 25 & 528 & 3.1 & \\
\hline
\end{tabular}

Study period had 51 deaths (3.7\%). Mortality profile (Table 2) was calculated after excluding DAMA and referred neonates as their outcome was unknown. Preterm and out born neonates died more than that of term and inborn neonates respectively $(\mathrm{p}<0.05)$. The death rates between LBW and normal birth weight babies was not statistically significant.

Table 3: Disease wise mortality $(n=51)$

\begin{tabular}{|l|c|c|c|c|c|c|c|}
\hline $\begin{array}{l}\text { Disease wise } \\
\text { deaths } \\
(\text { No and \%) }\end{array}$ & $\begin{array}{c}\text { Term } \\
(1056) \\
\text { No and \% }\end{array}$ & $\begin{array}{c}\text { Preterm } \\
(308) \text { No } \\
\text { and \% }\end{array}$ & P value & $\begin{array}{c}\text { Inborn( 900) } \\
\text { No and \% }\end{array}$ & $\begin{array}{c}\text { Out born (464) } \\
\text { No and \% }\end{array}$ & $\begin{array}{c}\text { p } \\
\text { value }\end{array}$ & $\begin{array}{c}\text { Case } \\
\text { Fatality } \\
\text { rate }\end{array}$ \\
\hline $\begin{array}{l}\text { Birth asphyxia } \\
(23,45 \%)\end{array}$ & $18(1.7)$ & $5(1.6)$ & 0.99 & $12(1.3)$ & $11(2.3)$ & 0.323 & $7.8 \%$ \\
$(23 / 294)$
\end{tabular}

The major causes of death were birth asphyxia (45\%), neonatal sepsis (27.5\%) and respiratory problems (27.5\%). HMD in Preterms and MAS in terms were the respiratory causes of death. Deaths due to sepsis were statistically significant among outborns when compared with inborn babies. Deaths due to respiratory causes in pre terms were statistically significant than that in term babies.

\section{Discussion}

Neonatal disease pattern varies from place to place and time to time even in the same place and it is a useful pointer of effectiveness of maternal and child health care services [8].This study aimed to assess mortality and morbidity pattern of NICU and to develop interventions for better outcome.

Demographic profile (table1) in this study showed inborn admissions $(63 \%)$ outnumbered outborns. Some studies showed more inborn admissions $73 \%$ and $83 \%$ respectively, while a study from Pakistan showed more out born admissions 55\% [9, 4, 10]. 59.6\% of admissions in our study is predominated by male neonates, which is similar to studies from Shivamogga and Pakistan that had 58\% and 63\% respectively [11, 10]. Our study had $89.8 \%$ newborn admissions within 7 days of birth similar to Prasad v study which had $85.5 \%$ admissions within 10days of birth, where as a study from Timor, Africa had only $27 \%$ of admission within 7 days of life $[9,12]$. In this study $25 \%$ of admission was by preterms and $40.6 \%$ by low birth weight babies. Admission contributed by preterm and Low birth weight babies by different studies were $34 \%$ and $51 \%$, $32 \%$ and $53 \%, 25.8 \%$ and $29 \%, 60.7 \%$ and $48.2 \%$ respectively[ $11,10,13,4]$. The above figures show that demographic profile is highly variable between different regions probably due to varied social, cultural, economic factors apart from availability of services.

Major causes of morbidity (figure1) in our study were neonatal sepsis (24\%), birth asphyxia including HIE (23.6\%). $40.5 \%$ and $25 \%$ of admission was due to LBW and preterm babies respectively. Of this $18.5 \%$ were primarily admitted for preterm or/ and LBW care in NICU for prolonged period. 
Studies from Africa reported sepsis in $37 \%$ and $38 \%$ of neonates which is higher than our study $[8,12]$. Sepsis was low $6.4 \%$ and $5.1 \%$ in studies from Bangladesh and Shivamogga [4, 11].A study from Bihar (23.3\%) had sepsis rates similar to the present study [14].Birth asphyxia (23.5\%) was high in our study; however a study from Bangladesh had 28.5\% [4]. Other studies showed the same to be lower than our study $12 \%, 18.5 \%$ and $7.1 \%[12,14,11]$.High incidence in our study is because of referral of many high risk pregnancies with fetal distress to our centre for delivery as evidenced by $22 \%$ of babies born with MSAF. In this study Respiratory problem (HMD, MAS, TTN and BP) was $13.9 \%$, while a study from Africa (22\%) had higher than ours [12]. Shivamogga study had $37.3 \%$ RDS [11]. Hyperbilirubinemia (10.3\%) in our study was low compared to other studies which reported $24 \%$ and 11 $\%[12,8]$. This could be due more term babies in this study and sometimes, phototherapy will be given to babies in postnatal ward without NICU admission.

Outcome of 1580 admitted babies (Figure2) 83\%were discharged home, very similar to studies which reported $81 \%$ and $82 \%$ discharges $[7,11]$. These two studies reported DAMA as $7.7 \%$ and $4 \%$ while a study from Maharashtra reported $31.7 \%$ [15]. Our study had $12.2 \%$ DAMA. Many babies leave the hospital before completion of treatment due to financial difficulties and also perhaps due to lack of hope of survival of sick babies. Our NICU death rate $(3.7 \%)$ was lowest compared to other studies which reported $13.4 \%$ and $10.7 \%[11,13]$. Probable reasons for this low rate are more inborn admissions, $75 \%$ were term babies, $59.5 \%$ had normal birth weight, and many well babies $(22 \%$ MSAF) were admitted to NICU for close monitoring before the development of any complications. Though DAMA and referrals were excluded for mortality rate calculation, they included potential life threatening conditions and could have influenced the current low mortality rate.

In this study out born deaths (Table2) were significantly more compared to inborn deaths which is similar to studies [11, 14]. Similarly, preterm deaths were significantly more when compared to the term babies as reported by many studies.

Birth asphyxia (Table-3) contributed to $45 \%$ of deaths in our study where as in other studies it was $31 \%$ and $8.5 \%[14,11]$. Neonatal sepsis in this study caused $27.5 \%$ of deaths, while an African study had $26 \%$, Rothera study had $34 \%$ and Shivamogga study had $5 \%$
[12, 14.11]. Respiratory problems caused $27.5 \%$ of deaths in our study where as in a study from Africa it caused $8.4 \%$ of deaths (12). Deaths of Preterm babies with respiratory problem (HMD) and out born babies with sepsis were statistically significant $(\mathrm{P}<0.05)$ in our study. Case fatality rates in our study due to respiratory causes were $8 \%$ followed by birth asphyxia $7.8 \%$ and neonatal sepsis 4.7 percent.

\section{Conclusions}

Birth asphyxia and neonatal sepsis are major causes of both morbidity and mortality. Other causes of morbidity are Respiratory problems, prematurity, low birth weight and hyperbilirubinemia. HMD in preterm and MAS in term babies are important respiratory causes of mortality.

This hospital based study may not reflect adequately the picture existing in the community. There is need to implement appropriate strategies to improve antenatal, intrapartum and postnatal care targeting to reduce birth asphyxia, neonatal infection and premature birth. Implementing child survival programmes like India Newborn Action Plan (INAP) 2014 may go a long way to reduce these preventable causes of neonatal morbidity and mortality.

Acknowledgements: My sincere thanks to Interns Dr. Anitha, Dr. Akhila, Dr. Jagadish and NICU staff for helping in Data Collection.

Ethical approval: Obtained from Institutional Ethics Committee (Human Studies)

Funding: No funding sources.

Conflict of Interest: The authors declare no conflict of interest.

\section{References}

1. Imoudu, Ahmad H, Yusuf MO, Makarfi, Umrah T. An Analysis of Neonatal Morbidity and Mortality in Azare, North- Eastern Nigeria.IOSR.2014; 13(3):25-28. doi:10.9790/0853-13312528

2. NFHS-3: Ministry of Health and Family Welfare, Govt. of India. Available at URL: http://www.mohfw.nic.in/NFHS-PRESENTATION. htm. (Accessed on 3rd September 2015).

3. UN Millennium Project. 2005. Investing in Development: A Practical Plan to Achieve the 
Millennium Development Goals. New York. (Accessed on $20^{\text {th }}$ september2015)

4. Nahar J, Zabeen B, Akhter S, Azad K, Nahar $\mathrm{N}$ : Neonatal morbidity and mortality pattern in the special care baby unit of BIRDEM. Ibrahim Med CollJ 2007; 1(2):1-4. doi: 10.3329/imcj.v1i2.2896

5. India Newborn Action Plan.Ministry of health and family welfare.Government of India. Available URL: http://www.newbornwhocc.org/INAP_Final.pdf. (Accessed on $20^{\text {th }}$ September 2015).

6. Bhutta ZA, Das JK, Bahl R et al. Can available interventions end preventable deaths in mothers, newborn babies, and stillbirths, and at what cost? Lancet. 2014 Jul 26; 384(9940):347-70. doi: 10.1016/S0140-6736(14)60792-3.

7. Elhassan EM, Hassanb AA, Mirghani OA, Adam I: Morbidity and mortality pattern of neonates admitted into nursery unit in Wad Medani Hospital, Sudan.Sudan J Med Science 2010; 5(1):1316.

8.Toma BO, Ige OO, Abok II, Onwuanaku C, Abah RO , Donli A. Pattern of neonatal admissions and outcome in a tertiary institution in north central Nigeria. Journal of Medicine in the Tropics.2013; 15(2): 121-125. doi: 10.4103/2276-7096.123590

9. Prasad V, Singh N. Causes of morbidity and mortality in neonates admitted in government medical college, Haldwaniin, Kumaun region, (Uttarakhand) India. Journal of pharmaceutical and biomedical science. JPBS, 2011; 8(8):1-4.
10. Hussain S. Neonatal Morbidity and Mortality Pattern in a Tertiary Care Neonatal Unit of a Teaching Hospital. Ann. Pak. Inst. Med. Sci.2014; 10(1):7-11.

11. Patil R, Koppad R, Benakanal S. Clinical Profile and Outcome of Babies Admitted to Neonatal Intensive Care Unit (NICU), Mc Gann Teaching Hospital Shivamogga, Karnataka: A Longitudinal Study. Sch. J. App. Med. Sci.2014; 2(6G):3357-3360.

12. Bucens IK, Reid A, Barreto AC, Dwivedi V, Counahan M. Three years of paediatric morbidity and mortality at the national hospital in Dili, East Timor. JPaediatr Child Health.2013; 49:1004-9.

13.Mmbaga BT, Lie RT, Olomi R, Mahande MJ, Kvale G, Daltveit AK. Cause-specific mortality in a neonatal care unit in Northern Tanzania: A registry based cohort study. BMC Pediatr.2012; 12:116. doi:10.1186/14712431-12-116

14. Mani Kant, Thakur S, Singh B. Study of the Morbidity and the Mortality Patterns in the Neonatal Intensive Care Unit at a Tertiary Care teaching Hospital in Rohtas District, Bihar, India. Journal of Clinical and Diagnostic Research. 2012 April; 6(2): 282-5. doi: JCDR/3687:1994

15. Salve D,Sarawade S, Doibale M, Tambe S, Sahu P. Study of Profile and Outcome of the Newborns Admitted In Neonatal Intensive Care Unit (NICU) At Tertiary Care Hospital in a City Of Maharashtra. IJHSR. 2015, [cited October 14, 2015]; 5(10): 18-23.

\section{How to cite this article?}

Chandrakala R Iyer, Gornale VK, Harsha P, Katwe N, Prasad S, Keerthivardhan Y. Morbidity and Mortality pattern of neonatal intensive care unit in a Medical College Hospital from South India. Pediatr Rev: Int J Pediatr Res 2015; 2(4):7782.doi:10.17511/ijpr.2015.i04.08 